\title{
Design and Experiments of the Sheet Electron Beam Transport with Periodic Cusped Magnetic Focusing for Terahertz Traveling-Wave Tubes
}

\author{
Changqing Zhang ${ }^{1}{ }^{\mathbb{D}}$, Pan Pan ${ }^{1}$, Xueliang Chen ${ }^{1}$, Siming Su ${ }^{1}$, Bowen Song ${ }^{1}$, Ying Li ${ }^{1}$, Suye Lü ${ }^{2}$, Jun Cai ${ }^{1}$, \\ Yubin Gong ${ }^{3}$ and Jinjun Feng ${ }^{1, *}$ \\ 1 National Key Laboratory of Science and Technology on Vacuum Electrics, Beijing Vacuum Electrics Research \\ Institute, Beijing 100015, China; c.q.zhang@163.com (C.Z.); p-pan@hotmail.com (P.P.); \\ chenxueliang0611@126.com (X.C.); 18645093816@163.com (S.S.); songbob6968@sina.com (B.S.); \\ ly18046510463@sina.com (Y.L.); caijun@sdu.edu.cn (J.C.) \\ 2 Institute of Nano-Photoelectronics and High Energy Physics, Beijing Institute of PetroChemical Technology, \\ Beijing 102617, China; lvsuye@bipt.edu.cn \\ 3 National Key Laboratory of Science and Technology on Vacuum Electronics, University of Electronic Science \\ and Technology of China, Chengdu 610054, China; ybgong@uestc.edu.cn \\ * Correspondence: fengjinjun@tsinghua.org.cn
}

check for

updates

Citation: Zhang, C.; Pan, P.; Chen, X.; Su, S.; Song, B.; Li, Y.; Lü, S.; Cai, J.; Gong, Y.; Feng, J. Design and Experiments of the Sheet Electron Beam Transport with Periodic Cusped Magnetic Focusing for Terahertz Traveling-Wave Tubes. Electronics 2021, 10, 3051. https://doi. org/10.3390/electronics10243051

Academic Editor: Yahya M. Meziani

Received: 9 November 2021

Accepted: 3 December 2021

Published: 7 December 2021

Publisher's Note: MDPI stays neutral with regard to jurisdictional claims in published maps and institutional affiliations.

Copyright: (c) 2021 by the authors. Licensee MDPI, Basel, Switzerland. This article is an open access article distributed under the terms and conditions of the Creative Commons Attribution (CC BY) license (https:// creativecommons.org/licenses/by/ $4.0 /)$.

\begin{abstract}
The successful transport of a sheet electron beam under the periodic cusped magnet (PCM) focusing at the terahertz frequencies is reported. The sheet beam with a current density of $285 \mathrm{~A} / \mathrm{cm}^{2}$ is intended for the developing G-band sheet-beam traveling-wave tube (TWT) whose operating voltage is nominally $24.5 \mathrm{kV}$. A beamstick was developed to validate the design of the electron optics system, which is considered as the most challenging part for developing a sheet-beam device. A beam transmission ratio of $81 \%$ is achieved over a distance of $37.5 \mathrm{~mm}$ at a cathode voltage of $-25.0 \mathrm{kV}$. The total current and the collector current were measured to be 125 and $102 \mathrm{~mA}$, respectively. The experimental results are promising, demonstrating that the PCM scheme is capable of focusing a highcurrent-density sheet beam and hence can find use in the terahertz TWTs, offering the advantages of compact size and light weight.
\end{abstract}

Keywords: Terahertz TWTs; sheet electron beam; PCM focusing; transmission of the sheet beam; vacuum electronic devices

\section{Introduction}

The sheet electron beam has been long considered for enhancing the performance of vacuum electronic devices (VEDs). However, the development of a sheet-beam device has been hindered for decades due to the difficulties in transport known as the "diocotron instability" [1,2]. Significant breakthroughs have been made in the last ten years. Several prototype devices have been successfully developed [3-7], which demonstrates the great potential of the sheet-beam technology, especially in power enhancement. Those inventions in many ways represent state-of-the-art technologies of developing VEDs except that most of them are based on solenoidal magnetic fields generated by the permanent magnets [8,9] whose volume and weight increase dramatically as the magnetic field peak and the transport distance increased. This is a major concern for using the sheet beam in a practical scenario such as the airborne radars and communication applications. Therefore, the periodic permanent magnet (PPM) focusing of the sheet beam is still attractive, although its application is found to be limited to transporting a sheet beam with low voltage and high current density [9].

The PCM focused sheet-beam TWT was first demonstrated at Ka band with beam transmission of $93 \%$ with a voltage of $24.3 \mathrm{kV}$ [10]. At the same frequency band, a PCMfocused high-power sheet-beam TWT was recently reported [11] with a CW power output 
of up to $3 \mathrm{~kW}$, along with a transmission of $97 \%$ at a voltage of $30.9 \mathrm{kV}$ and a current of 0.82 A. In addition, a W-band PCM-focused sheet-beam extended-interaction oscillator (EIO) was demonstrated with a transport of $94.4 \%$ at a high operating voltage of $\sim 47 \mathrm{kV} \mathrm{[12].}$ However, it remains a challenge for the PCM scheme to transport a low-voltage highcurrent-density sheet beam for the terahertz TWTs. The reasons come from both the insufficient capacity of the magnet material itself and the structural limitations from the reduced size of the circuit. Thus, compromises have to be made between the desired the high current and the achievable magnetic fields. We recently performed a theoretical review of the PCM focusing, along with the design of a magnetic field system [13]. As a key step of developing the sheet-beam TWT, a beamstick was developed. This paper presents a complete design of the electron optical system. The experimental results are also reported for the first time.

\section{Design of the Electron Gun}

The design of the electron gun was based on the CST (Computer Simulation Technology) Particle Tracking Solver. The nominal design parameters are listed in Table 1. The simulation model is shown in Figure 1. Basically, this is a Pierce-type gun with the exception that the cross sections of the cathode and the focusing electrode are conformal ellipses, as shown in Figure 1b. To facilitate the assembly, the shape of the electrodes is designed as simply as possible. Consequently, both the cathode emission surface and the anode entrance are planar. In the tracking simulation, we enable the gun iteration option to ensure the convergence of the emitting current. The effects of the space-charge field and the self-magnetic field of the beam are also considered in the simulation. The 2D particle monitors were deployed along the beam transport direction with an interval of $0.1 \mathrm{~mm}$. As a result, the position and other statistical information of the particles can be derived by these monitors.

Table 1. Design parameters of the sheet-beam electron gun.

\begin{tabular}{cc}
\hline Parameters & Value (Unit) \\
\hline Cathode voltage $V_{0}$ & $24.5 \mathrm{kV}$ \\
Emission current $I_{0}$ & $0.135 \mathrm{~A}$ \\
Cathode size & $0.85 \times 0.65 \mathrm{~mm}^{2}$ \\
Beam waist size & $0.6 \times 0.11 \mathrm{~mm}^{2}$ \\
Tunnel size & $0.8 \times 0.2 \mathrm{~mm}^{2}$ \\
\hline
\end{tabular}

${ }_{1}^{1}$ The cross section of the beam is an ellipse. Thus, the dimension of beam is determined by the major axis and the minor axis of the ellipse.
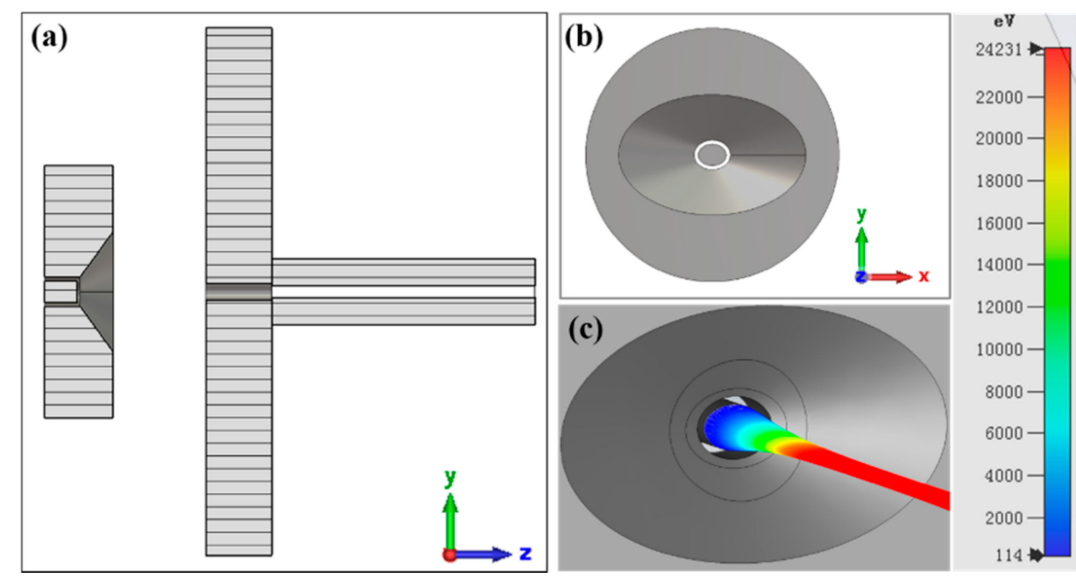

Figure 1. The CST model of the sheet-beam electron gun: (a) the cross section of the model, (b) the front view of the cathode and focus electrode, and (c) the beam formation with the elliptical focus electrode. 
Figure 2 shows the convergence of the emitting current. The simulation predicted a current of $135 \mathrm{~mA}$ at a cathode voltage of $24.5 \mathrm{kV}$. The resulting cathode loading is $31.1 \mathrm{~A} / \mathrm{cm}^{2}$, which exceeds the capacity of the ordinary M-type cathodes. Thus, the scandate cathode is used.

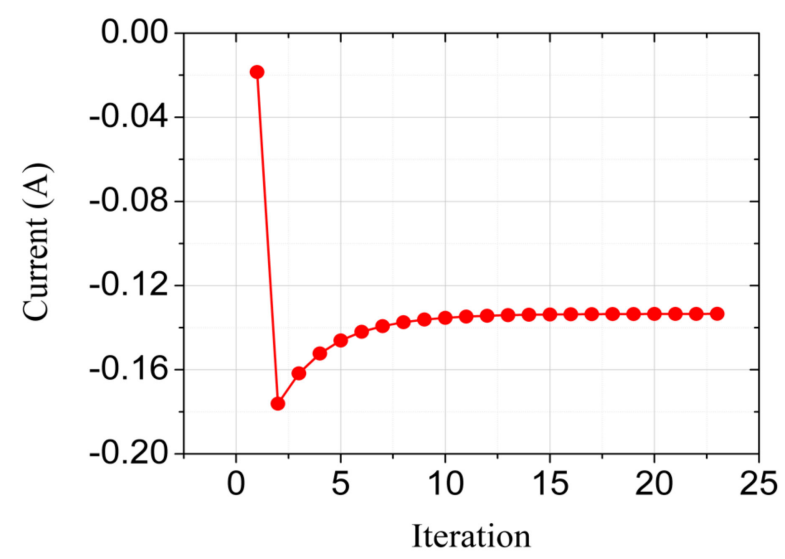

Figure 2. The convergence of the emitting current.

Figure 3 shows the electrostatic trajectory envelopes of the sheet beam. We can see that the gun provides an excellent laminar property for the sheet beam. The electron beam is compressed in both directions. However, the major contribution to the compression ratio comes from the vertical direction $(\mathrm{Y})$. The position of the beam waist in the vertical direction is basically the same as that in the horizontal direction, which is about $7.8 \mathrm{~mm}$. The compression ratios of the horizontal and vertical directions are 1.37 and 6.5, respectively, corresponding to an overall area compression ratio of 8.9. Figure 4 demonstrates the phase space of the compressing process where the two cross sections correspond to the emission surface and the beam waist, respectively. We can see that the sheet beam maintains its shape well during the compressing process, and no over-compressed phenomenon is observed at the edges of the beam.

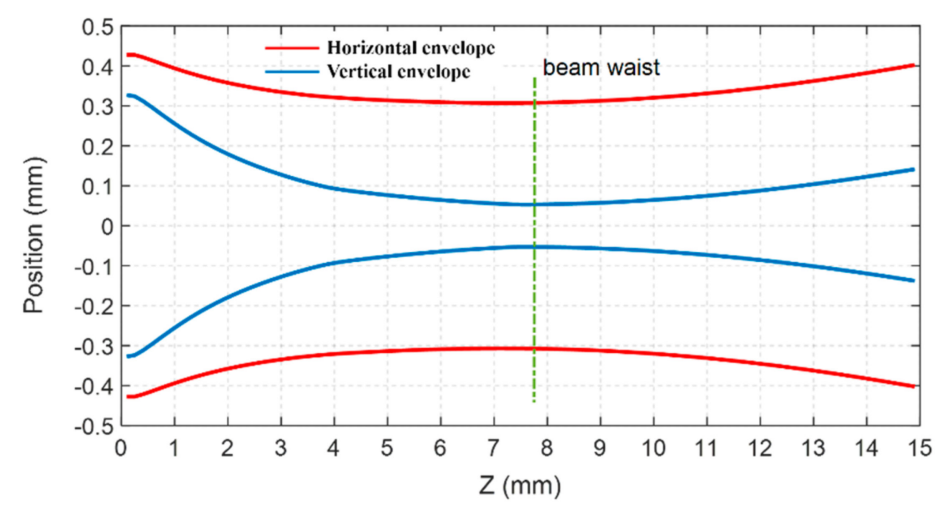

Figure 3. The envelopes of the electrostatic trajectories of the sheet beam. 


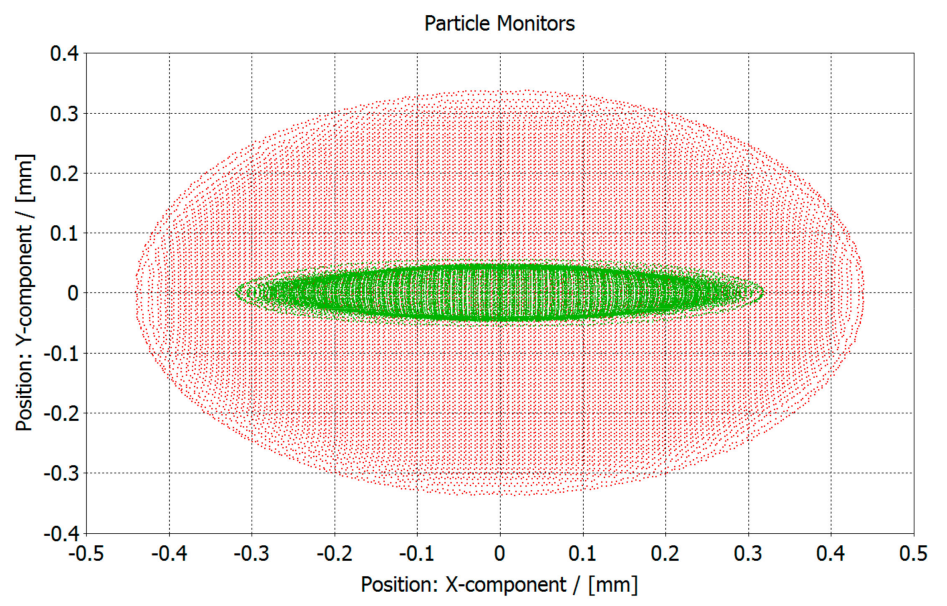

Figure 4. Compression of the sheet beam from emission surface to the waist.

\section{Design of the PCM Focusing System}

The stable transmission of the sheet beam under the periodically focusing magnetic fields requires the two-plane focusing, i.e., both the vertical and the horizontal directions need to be considered. Several focusing schemes can realize that. Here, a modified offset-pole-piece PCM scheme [13] is used. The model of the focusing system is shown in Figure 5. The arrows in the magnets denote the direction of the magnetization. The CST Magnetostatic Solver was used for the design of the magnet system. The parameters of the magnetic system are listed in Table 2. In the simulation, the iron material is assumed for the pole pieces with a nonlinear $B-H$ relationship.
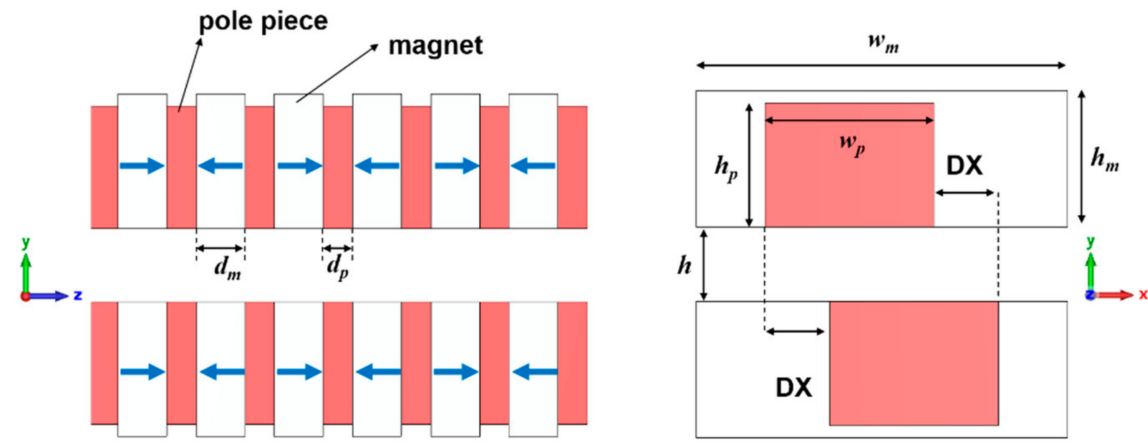

Figure 5. Schematic diagram of the PCM focusing system.

Table 2. Parameters of the magnet system.

\begin{tabular}{cc}
\hline Parameters & Value (Unit) \\
\hline$B_{r}$ & $1.09 \mathrm{~T}$ \\
$L_{m}$ & $6.4 \mathrm{~mm}$ \\
$h$ & $3.0 \mathrm{~mm}$ \\
$w_{m} \times h_{m} \times d_{m}$ & $15 \times 5.5 \times 2.0 \mathrm{~mm}^{3}$ \\
$w_{p} \times h_{p} \times d_{p}$ & $6.8 \times 5.0 \times 1.2 \mathrm{~mm}^{3}$ \\
\hline
\end{tabular}

Figure 6a shows the distribution of the on-axis magnetic field $B_{z}$. It can be seen that a peak of $0.38 \mathrm{~T}$ is achieved. Figure $6 \mathrm{~b}$ plots the distribution of $B_{y}$ along the longitudinal direction at the beam sides $X= \pm 0.3 \mathrm{~mm}$ and $Y=0$. This magnetic field is denoted as the

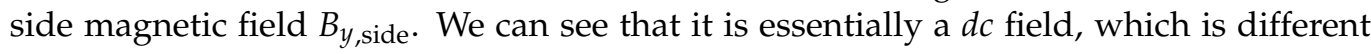
from $B_{z}$. Thus, the mechanism for horizontal focusing is different from that of the vertical focusing. The theory predicted that a value of $10^{-3} \mathrm{~T}$ for $B_{y}$ is required to counter the 
space-charge defocusing effect from $E_{s p, x}$. We can see from Figure $6 \mathrm{~b}$ that the design meets the requirement.
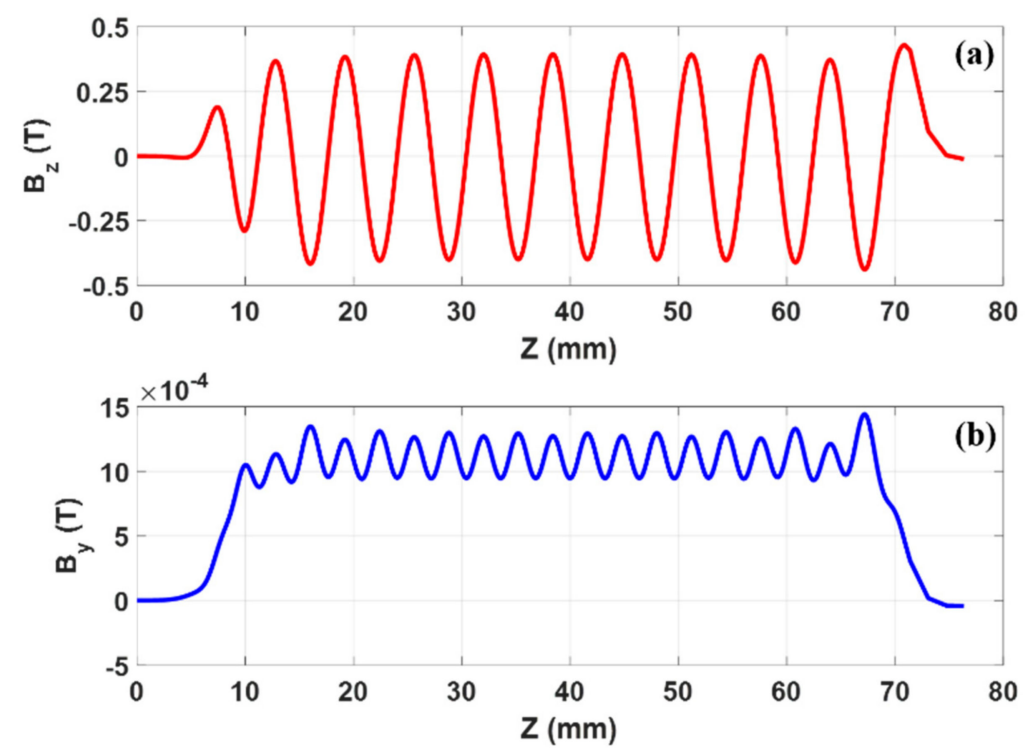

Figure 6. Design results of the focusing magnetic fields: (a) the on-axis distribution of $B_{z}$, (b) the side magnetic field $B_{y, \text { side }}$ at $X= \pm 0.3 \mathrm{~mm}$ and $Y=0$.

The unique distribution of $B_{y \text {,side }}$ is highly sensitive to the position, as is illustrated in Figure 7 , where $d Y$ denotes the position deviation from the $Y=0$ plane with $X=0.3 \mathrm{~mm}$

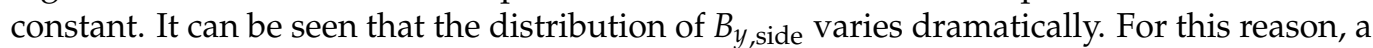
means of tuning the side magnetic field is critical in practice.

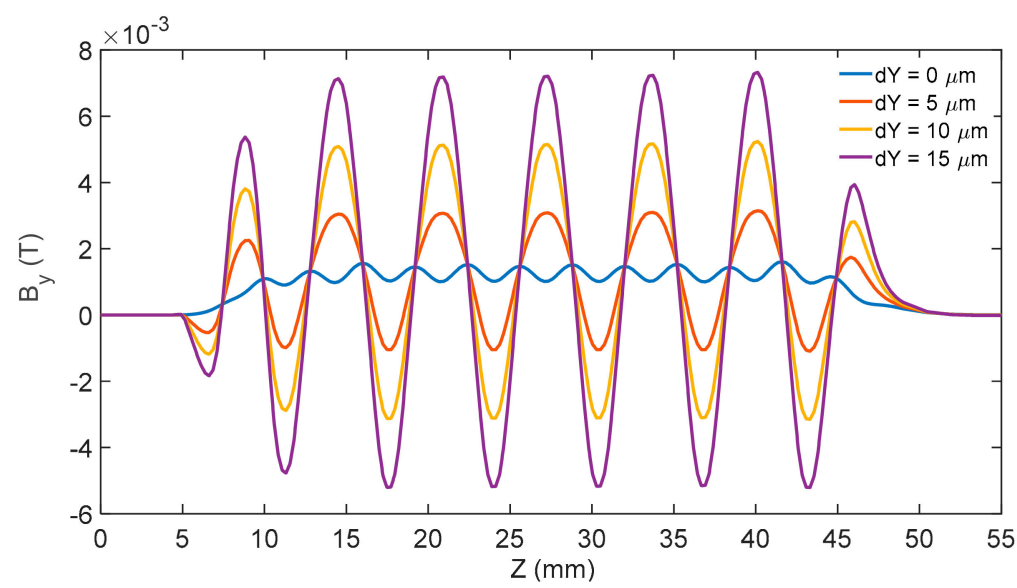

Figure 7. Sensitivity analysis of the side magnetic field $B_{y, \text { side }}$.

By importing the designed magnetic fields into the electron gun model, a complete electron optical simulation can be achieved. Figure 8 shows the formation and transmission of the sheet beam under the designed focusing magnetic fields. It can be seen that the sheet beam is well confined in both directions. Moreover, although the horizontal envelope of the sheet beam is highly sensitive to the side magnetic field, the vertical focusing is nearly independent of the side focusing. This is the basis of tuning the side magnetic field in practice. 

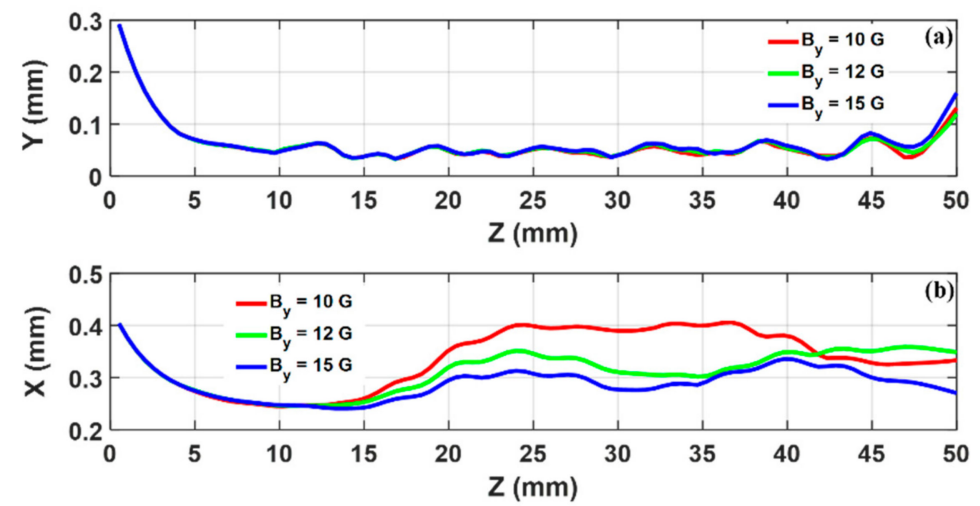

Figure 8. Simulations of the sheet beam transmission under the designed focusing magnetic fields with the side magnetic field $B_{y}$,side varied: (a) the trajectories envelopes in vertical direction and (b) the trajectories envelopes in horizontal direction.

In light of the importance of the magnetic field system, efforts have been made to measure the magnetic field distributions. The measuring platform is demonstrated in Figure $9 \mathrm{a}$. This is a three-dimensional auto-measuring platform, which can provide a position-shifted accuracy of $10 \mu \mathrm{m}$ and a magnetic field measurement accuracy of $10^{-6} \mathrm{~T}$. The results are shown in Figure 9b,c with simulation results compared. Note that since the space between the two magnet arrays is too small to insert the probe in terms of the design value of $h=3.0 \mathrm{~mm}$, we have to enlarge the space. As a result, the peak of the magnetic fields was reduced. However, we can see that the measured distribution of $B_{z}$ is in good agreement with the simulation. Although discrepancy can be observed in $B_{y}$, the agreement is fair considering the sensitivity of the side magnetic field.
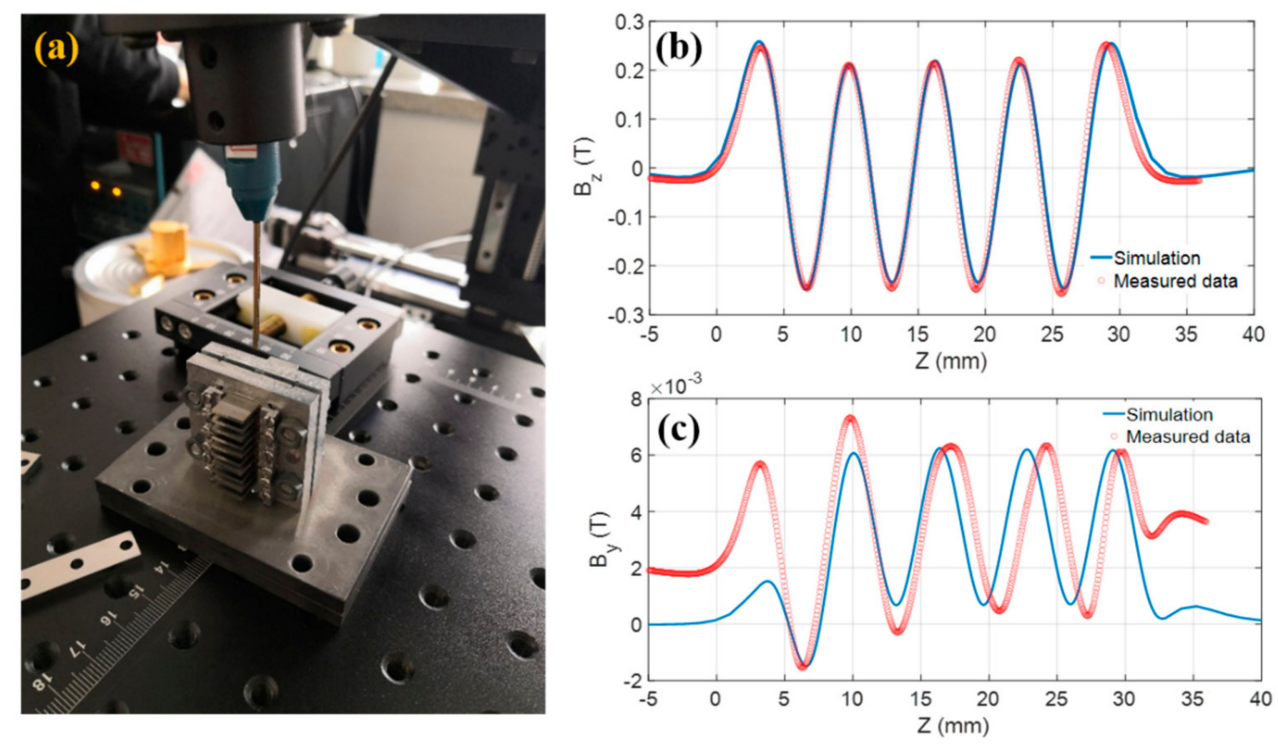

Figure 9. (a) The magnetic field measurement platform, (b) the measured axial magnetic field distribution $B_{z}$, and (c) the measured side magnetic field $B_{y}$.

\section{Experimental Results}

Experiments have been carried out to verify the design of the sheet-beam electron optical system. A beamstick was assembled without the need for RF input/output coupler, where the interaction circuit is replaced by a rectangular tunnel of $0.75 \times 0.2 \mathrm{~mm}^{2}$. The tunnel size is consistent with that of an actual interaction circuit. The transmission distance is $37.5 \mathrm{~mm}$ from the anode entrance to the collector. Such a distance is sufficient to support an amplification up to $18 \mathrm{~dB}$. 
Figure 10 demonstrates the beamstick in the testing site. The performance of the beamstick was measured under the pulse mode with pulse durations of 10-50 $\mu$ s and repetition rates of $100 \mathrm{~Hz}$. The body and the collector currents are measured by the ammeters and simultaneously confirmed with the oscilloscope. Figure 11 shows current waveforms for different pulse durations.

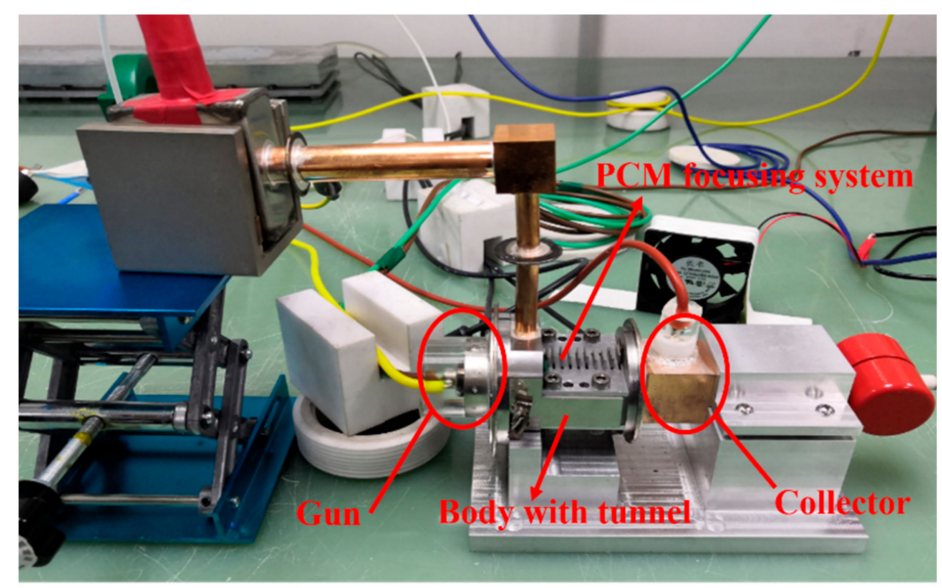

Figure 10. The beamstick in the testing site.

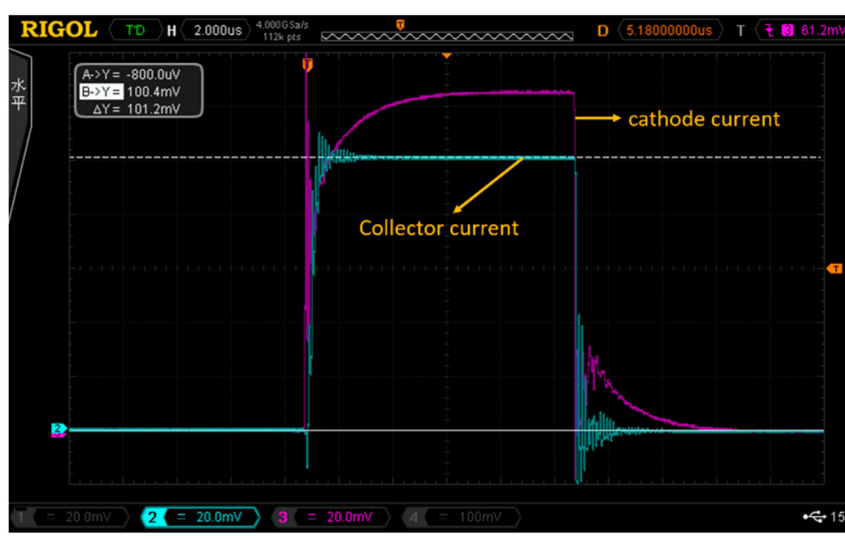

(a)

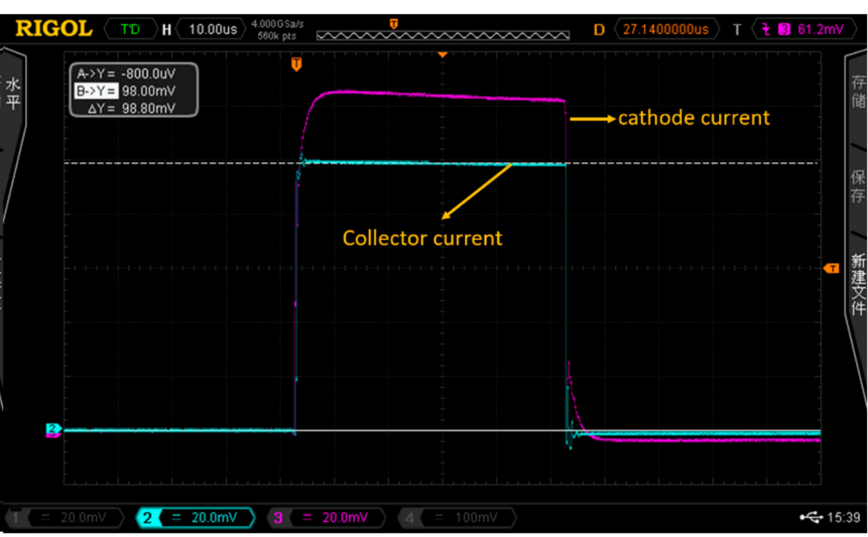

(b)

Figure 11. The current waveforms measured by oscilloscope with (a) pulse durations of $10 \mu$ s and (b) pulse durations of $50 \mu \mathrm{s}$. Both cases have the same repetition rates of $100 \mathrm{~Hz}$.

Figure 12 plots the measured cathode emission current. At $1050{ }^{\circ} \mathrm{C}$, corresponding to a filament heating power $\sim 4.4 \mathrm{~W}$, the emission current was measured to be $125 \mathrm{~mA}$, corresponding to a cathode loading of $28.8 \mathrm{~A} / \mathrm{cm}^{2}$. The current is slightly lower than the design value of $135 \mathrm{~mA}$ due to the biased voltage applied to the focus electrode. By reducing the biased voltage, the emission can approach $146 \mathrm{~mA}$. Thus, the scandate cathode can provides sufficient emission for the sheet-beam gun. 


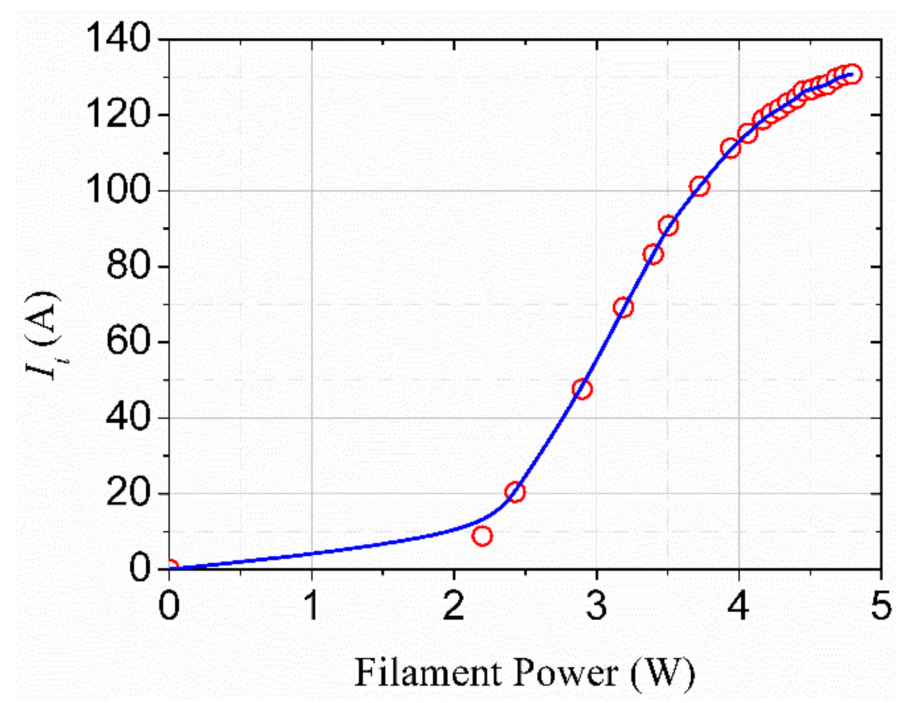

Figure 12. The emission current of the Scandate cathode as a function of the filament power.

Figure 13 shows the total current $I_{t}$ and the collector current $I_{c}$ as a function of the cathode voltage. It can be seen that the total current $I_{t}$ increases almost linearly with the increase of the cathode voltage. The collector current $I_{c}$ is small and rises slowly when the voltage is less than $18 \mathrm{kV}$, but it increases fast after that. An optimal transport efficiency over $81 \%$ was obtained at a voltage of $-25 \mathrm{kV}$, which is slightly higher than the design value of $-24.5 \mathrm{kV}$. The corresponding total current and collector current are 125 and $102 \mathrm{~mA}$, respectively.

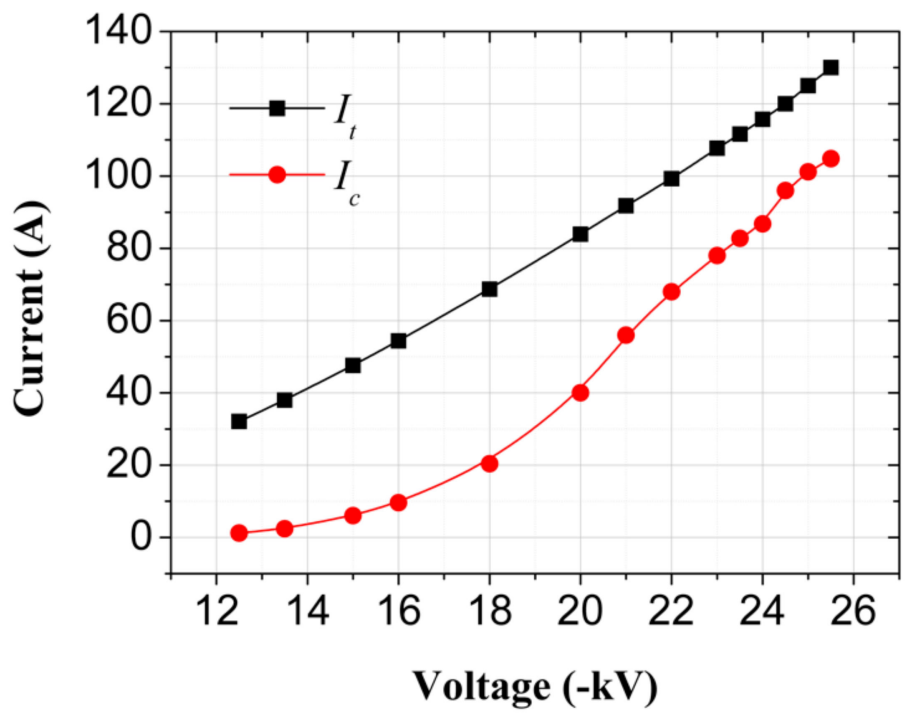

Figure 13. The measured currents as a function of the cathode voltage.

From the measured currents, we can estimate that the cutoff voltage of the PCM system is about $19 \mathrm{kV}$. Such a high cutoff voltage, which is close to the nominal operating voltage $(24.5 \mathrm{kV})$, indicates that the PCM system may approach its limit of capacity. That is why the voltage corresponding to the optimal transport efficiency is higher than the nominal operating voltage. Due to the difficulty in achieving a higher peak of the magnetic field system, the voltage has to be increased to achieve the optimal transport efficiency.

Figure 14 shows the effect of the biased focus voltage (BFV) on the currents and the transport efficiency. It can be seen that both the collector current and the transport efficiency are significantly increased as the BFV increased before it reaches $-85 \mathrm{~V}$. As the BFV goes further, the increase of the transport efficiency is mainly attributed to the decrease of the 
total current. Due to the thermal expansion effect of the cathode and the inevitable errors in assembling, the required BFV is found to be much higher than expected. This is also the reason that the total current is lower than the design value at the nominal voltage of $24.5 \mathrm{kV}$.

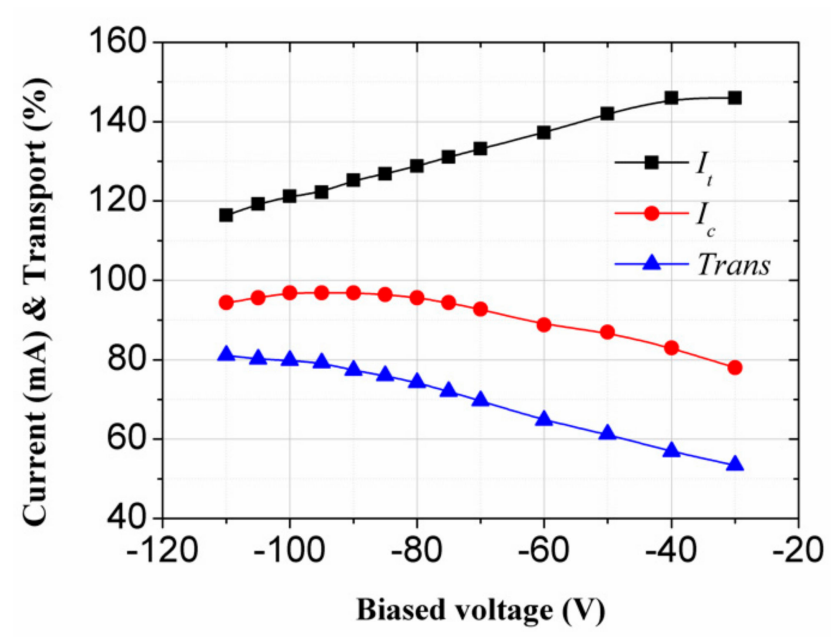

Figure 14. The measured current and the transport efficiency as a function of the biased focus voltage.

Table 3 compared the beam parameters and the transport efficiencies of the sheetbeam TWTs, which were reported with the experimental results. To make the comparison meaningful for different frequencies, the normalized transport distance was used, which is defined as $L / \lambda_{0}$, where $\lambda_{0}=c / f_{0}, L$ is the actual transmission distance, $f_{0}$ is the central frequency, and $c$ is the speed of light in vacuum. We specify $f_{0}$ as $14,35,44,94$, and $220 \mathrm{GHz}$ for the $\mathrm{Ku}, \mathrm{Ka}, \mathrm{Q}, \mathrm{W}$, and $\mathrm{G}$ band. It can be seen clearly from the table that this paper demonstrated the highest level in the cathode emitting capacity, beam current density, and normalized transport distance among the PCM focused TWTs. In particular, the transmission current density is nearly five times higher than that of the Ka-band TWT. Considering the more stringent requirements for tolerance in terahertz frequencies, we can conclude that a substantial breakthrough has been made in the long-distance transmission of the PCM focused sheet beam. The focusing with a permanent magnet solenoid allows a higher current density because a very large magnetic field $(0.85 \sim 1 \mathrm{~T})$ can be achieved. However, the disadvantages in volume and weight limit the use of a permanent magnet solenoid in TWTs.

Table 3. Comparison of the electron optical parameters of the sheet-beam TWTs, which were reported with experimental results.

\begin{tabular}{|c|c|c|c|c|c|c|c|c|c|}
\hline Devices & Band & $\begin{array}{l}\text { Focusing } \\
\text { Scheme }\end{array}$ & $\begin{array}{l}\text { Voltage } \\
(\mathrm{kV})\end{array}$ & $\begin{array}{l}\text { Current } \\
\text { (A) }\end{array}$ & $\begin{array}{c}\text { Beam Size and Cathode } \\
\text { Size }\end{array}$ & $\begin{array}{l}\text { Cathode } \\
\text { Loading } \\
\left(\mathrm{A} / \mathrm{cm}^{2}\right)\end{array}$ & $\begin{array}{l}\text { Current } \\
\text { Density } \\
\left(\mathrm{A} / \mathrm{cm}^{2}\right)\end{array}$ & $\begin{array}{l}\text { Normalized } \\
\text { Transport } \\
\text { Distance }\end{array}$ & $\begin{array}{c}\text { Transport } \\
\text { Efficiency } \\
(\%)\end{array}$ \\
\hline This paper & G & PCM & 24.5 & 0.135 & $\begin{array}{l}0.60 \times 0.11 \mathrm{~mm}^{2} \\
0.85 \times 0.65 \mathrm{~mm}^{2}\end{array}$ & 31.1 & 285 & 27.5 & 81 \\
\hline TWT [10] & Ка & PCM & 24.3 & 0.8 & $\begin{array}{l}3.2 \times 0.6 \mathrm{~mm}^{2} \\
3.2 \times 1.8 \mathrm{~mm}^{2}\end{array}$ & 17.68 & 53.05 & 13.16 & 93 \\
\hline TWT [11] & Ка & PCM & 30.9 & 0.82 & $\begin{array}{c}4.0 \times 0.4 \mathrm{~mm}^{2} \\
\quad 110: 1\end{array}$ & 6.366 & 63.66 & 17 & 97 \\
\hline TWT [14] & $\mathrm{Ku}$ & PCM & 34 & 4 & $\begin{array}{c}8.0 \times 0.9 \mathrm{~mm}^{2} \\
10: 1\end{array}$ & 7.073 & 70.73 & 14 & 81 \\
\hline TWT [14] & Q & PCM & 30 & 1.2 & $\begin{array}{c}3.0 \times 0.4 \mathrm{~mm}^{2} \\
10: 1\end{array}$ & 12.73 & 127.3 & 17 & 92 \\
\hline $\begin{array}{l}\text { Beamstick } \\
{[3,5,8]}\end{array}$ & $\mathrm{W} / \mathrm{Ka}$ & Solenoid $^{2}$ & 20 & 4 & $\begin{array}{c}4 \times 0.25 \mathrm{~mm}^{2} \\
4 \times 10 \mathrm{~mm}^{2}\end{array}$ & 10 & 400 & 6.27 & 98.5 \\
\hline TWT [4] & G & Solenoid & 22.88 & 0.23 & $\begin{array}{c}0.7 \times 0.1 \mathrm{~mm}^{2} \\
0.86 \times 1.06 \mathrm{~mm}^{2}\end{array}$ & 38 & 438 & 29.35 & 78.3 \\
\hline
\end{tabular}

\footnotetext{
${ }^{1}$ The dimensions of the cathode cannot be found but the compression ratios were given. ${ }^{2}$ Permanent magnet solenoid.
} 


\section{Conclusions}

Efforts have been made in the design, fabrication, assembly, and measurement to achieve a PCM-focused sheet electron beam for the terahertz TWTs. A beamstick was developed and tested. A transport efficiency over $81 \%$ was measured with a total current of $125 \mathrm{~mA}$ and a collector current of $102 \mathrm{~mA}$. The total current is slightly lower than the design value due to an increased focus voltage. Although such a current is still at an intermediate level for a sheet beam, it is two times higher than that of a circular beam with PPM focusing at the same frequencies. Thus, the performance enhancement of the TWT with a sheet beam can be expected.

Author Contributions: Conceptualization, C.Z. and J.F.; methodology, C.Z., P.P., and J.C.; software, S.L.; validation, C.Z., P.P., and J.C.; data curation, X.C., S.S., B.S., and Y.L.; writing-original draft preparation, C.Z.; writing-review and editing, J.F. and C.Z.; supervision, J.F.; project administration P.P., J.C and Y.G. All authors have read and agreed to the published version of the manuscript.

Funding: This research was funded by the Natural Science Foundation of China (Grant No. 62131006, 61921002, 61831001, 92163204) and the Beijing Natural Science Foundation (Grant No. 1192007), The Scientific Research Project of Beijing Educational Committee under Grant KM202010017010.

Conflicts of Interest: The authors declare no conflict of interest.

\section{References}

1. Cutler, C.C. Instability in Hollow and Strip Electron Beams. J. Appl. Phys. 1956, 27, 1028-1029. [CrossRef]

2. Booske, J.H.; McVey, B.D.; Antonsen, T.M. Stability and confinement of nonrelativistic sheet electron beams with periodic cusped magnetic focusing. J. Appl. Phys. 1993, 73, 4140-4155. [CrossRef]

3. Pasour, J.; Wright, E.; Nguyen, K.T.; Balkcum, A.; Wood, F.N.; Myers, R.E.; Levush, B. Demonstration of a Multikilowatt, Solenoidally Focused Sheet Beam Amplifier at 94 GHz. IEEE Trans. Electron. Devices 2014, 61, 1630-1636. [CrossRef]

4. Gamzina, D.; Himes, L.G.; Barchfeld, R.; Zheng, Y.; Popovic, B.K.; Paoloni, C.; Choi, E.; Luhmann, N.C. Nano-CNC Machining of Sub-THz Vacuum Electron Devices. IEEE Trans. Electron. Devices 2016, 63, 4067-4073. [CrossRef]

5. $\quad$ Pershing, D.E.; Myers, R.E.; Levush, B.; Nguyen, K.T.; Abe, D.K.; Wright, E.; Larsen, P.B.; Pasour, J.; Cooke, S.; Balkcum, A.; et al. Demonstration of a Wideband 10-kW Ka-Band Sheet Beam TWT Amplifier. IEEE Trans. Electron. Devices 2014, 61, 1637-1642. [CrossRef]

6. Cusick, M.; Atkinson, J.; Balkcum, A.; Caryotakis, G.; Gajaria, D.; Grant, T.; Meyer, C.; Lind, K.; Perrin, M.; Scheitrum, G.; et al. X-Band Sheet Beam Klystron (XSBK). In Proceedings of the 2009 IEEE International Vacuum Electronics Conference, Rome, Italy, 28-30 April 2009; pp. 296-297. [CrossRef]

7. Zhao, D.; Lu, X.; Liang, Y.; Yang, X.; Ruan, C.; Ding, Y. Researches on an X-Band Sheet Beam Klystron. IEEE Trans. Electron. Devices 2013, 61, 151-158. [CrossRef]

8. Pasour, J.; Nguyen, K.; Wright, E.; Balkcum, A.; Atkinson, J.; Cusick, M.; Levush, B. Demonstration of a 100-kW Solenoidally Focused Sheet Electron Beam for Millimeter-Wave Amplifiers. IEEE Trans. Electron. Devices 2011, 58, 1792-1797. [CrossRef]

9. Nguyen, K.T.; Pasour, J.A.; Antonsen, T.M.; Larsen, P.B.; Petillo, J.J.; Levush, B. Intense Sheet Electron Beam Transport in a Uniform Solenoidal Magnetic Field. IEEE Trans. Electron. Devices 2009, 56, 744-752. [CrossRef]

10. Shi, X.; Wang, Z.; Tang, T.; Gong, H.; Wei, Y.; Duan, Z.; Tang, X.; Wang, Y.; Feng, J.; Gong, Y. Theoretical and Experimental Research on a Novel Small Tunable PCM System in Staggered Double Vane TWT. IEEE Trans. Electron. Devices 2015, 62, 4258-4264. [CrossRef]

11. Wang, J.; Wan, Y.; Li, X.; Liu, Q.; Li, H.; Yao, Y.; Zheng, Q.; Wu, Z.; Jiang, W.; Liu, G.; et al. Continuous Wave Operation of a Ka-Band Broadband High-Power Sheet Beam Traveling-Wave Tube. IEEE Electron. Device Lett. 2021, 42, 1069-1072. [CrossRef]

12. Wang, J.; Li, X.; Rui, L.; Liu, Z.; Liu, G.; Jiang, W.; Wu, Z.; Hu, Y.; Luo, Y. Experimental Study of a 6 kW W-band PCM Focused Sheet Beam EIO. In Proceedings of the 2019 International Vacuum Electronics Conference (IVEC), Busan, Korea, 28 April-1 May 2019; pp. 1-2.

13. Zhang, C.; Feng, J.; Cai, J.; Pan, P.; Su, S.; Gong, Y. Focusing of the Sheet Electron Beam with Two-Plane Periodic Cusped Magnetic System for Terahertz TWTs. IEEE Trans. Electron. Devices 2021, 68, 3056-3062. [CrossRef]

14. Wang, J.; Liu, G.; Shu, G.; Zheng, Y.; Yao, Y.; Luo, Y. The PCM focused millimeter-wave sheet beam TWT. In Proceedings of the 2017 Eighteenth International Vacuum Electronics Conference (IVEC), London, UK, 24-26 April 2017; pp. 1-3. 